\title{
Design of stainless steel continuous beams with tubular cross-sections
}

\author{
I. Arrayago, E. Real, E. Mirambell \\ Department of Civil and Environmental Engineering, Universitat Politècnica de Catalunya - \\ BarcelonaTech, Jordi Girona 1-3, C1 Building (room 207), Barcelona 08034, Spain \\ Corresponding author: I. Arrayago Tel: +34 934054156; Fax: +34 934054135, \\ e-mail: itsaso.arrayago@upc.edu
}

\begin{abstract}
This paper presents a comprehensive study on the application of global plastic design methods, not currently allowed in European specification provisions, to stainless steel rectangular and square hollow section continuous beams. The analysis of experimental and numerical continuous beam strengths highlighted that ultimate capacity predictions calculated based on global elastic analysis result in a considerable conservatism due to strain hardening and bending moment redistribution effects. Alternatively, the assessment and reliability analyses of the traditional plastic design methods demonstrated that the Class 1 cross-section limit provided in the European specification can be safely applied for the partial safety factor $\gamma_{\mathrm{M} 0}$ currently provided. However, the analysis evidenced that including bending moment redistribution in capacity predictions is not enough since strain hardening effects play an important role when stocky crosssections are analysed. Thus, the Continuous Strength Method for indeterminate structures was also assessed and it was found to provide accurate capacity predictions for all analysed stainless steel grades. Finally, an alternative Direct Strength Method design approach is proposed for stainless steel continuous beams based on the Direct Strength Method bending capacity. The proposed method, statistically validated, accounts for strain hardening effects and moment redistribution and provides the best resistance predictions among the different design methods considered.
\end{abstract}




\section{HIGHLIGHTS}

- The applicability of global plastic design for stainless steel continuous beams is investigated.

- Existing Class 1 limits are statistically assessed.

- The CSM approach for indeterminate structures is also evaluated.

- New DSM-based approach is proposed for stainless steel continuous beams.

- Plastic design approaches including strain hardening provide best capacity predictions.

\section{KEYWORDS}

continuous beam; Continuous Strength Method; Direct Strength Method; global plastic design; stainless steel

\section{Introduction}

It is widely recognized that the behaviour of stainless steel is considerably different from that exhibited by structural carbon steel, with a nonlinear stress-strain response even for low strain levels. Carbon steel presents an elastic region with a clearly defined yield point, usually followed by a yield plateau. In opposition to this elastic-perfectly plastic material, stainless steels present a nonlinear stress-strain response where no clearly defined yield point is identified, which is conventionally determined as the proof stress for a $0.2 \%$ offset strain. In addition to the improved corrosion resistance against carbon steels, stainless steels exhibit considerable strain hardening and high ductility, with strains at fracture reaching 40-60 \% for the most ductile austenitic grades. However, the behaviour of stainless steel grades has been assumed to be similar to that exhibited by carbon steel in the different existing standards (e.g. EN1993-1-4 [1], 
AS/NZS4673 [2], SEI/ASCE 8-02 [3]), usually leading to overconservative design provisions.

Development of efficient design guidance for stainless steel structures is key for the increased use of this corrosion-resistant material by considering both its nonlinear behaviour and strain hardening effects into resistance predicting expressions, together with the moment redistribution in indeterminate structures. Research efforts have mainly focused on the resistance prediction of stainless steel cross-sections and members, where different methods accounting for strain hardening effects have been proposed. The Continuous Strength Method (CSM) developed for austenitic and duplex stainless steels by Afshan and Gardner [4] and adapted to ferritics by Bock et al. [5]; and the Direct Strength Method (DSM) approach that considers strain hardening effects proposed by Rossi and Rasmussen [6] and Arrayago et al. [7].

Although no plastic design is allowed for stainless steel structures in EN1993-1-4 [1], various research works analysed the bending moment redistribution capacity of stainless steel structures and the applicability of plastic design methods, provided that stainless steel indeterminate structures with stocky cross-sections possess high deformation capacity prior to collapse. This paper presents the assessment of the different global plastic design approaches based on extensive experimental and numerical databases, where the accuracy and reliability of these approaches are investigated. The traditional plastic design method given in EN1993-1-1 [8] and the alternative Continuous Strength Method (CSM) for indeterminate structures (Gardner et al. [9] and Theofanous et al. [10]) have been considered in the analysis. This paper also presents a new Direct Strength Method (DSM) approach for stainless steel continuous beams based on the DSM bending capacity approach, which accounts for both strain hardening effects and 
the bending moment redistribution capacity of the beams, and the reliability of the method is demonstrated by means of statistical analyses.

\section{Gathered experimental data and FE ultimate strengths}

The different analyses and proposals presented in this paper are based on an extensive strength database comprising both experimental and numerical results for several stainless steel grades. This section first presents the collated experimental database and offers all the relevant information regarding the finite element model validation and the conducted parametric studies.

\subsection{Collected experimental data}

The number of available tests on hollow section stainless steel continuous beams is very limited: while Theofanous et al. [10] and Real and Mirambell [11] reported 14 continuous beam test results on the most common austenitic stainless steel EN1.4301 grade, Arrayago and Real [12] provided experimental data on ferritic EN1.4003 alloy two span continuous beams.

\subsection{FE model validation and parametric studies}

In addition to the available experimental database, parametric studies based on finite element (FE) modelling have been performed in order to provide a comprehensive assessment of the global plastic design methods. These FE models procured ultimate strengths of continuous beams with stocky cross-sections by testing virtual specimens with cross-sections not covered by the existing experimental programmes. This section presents the validation of the FE models for ferritic stainless steel Rectangular and Square Hollow Section (RHS and SHS) continuous beams over two span configurations based on the experimental results conducted by the authors and reported in [12] and also summarizes the conducted parametric studies. The configuration of the reference tests 
reported in [12] is shown in Figure 1. $3200 \mathrm{~mm}$ long beams were tested under a fivepoint bending configuration over two $1500 \mathrm{~mm}$ long spans, each subjected to a concentrated midspan load.

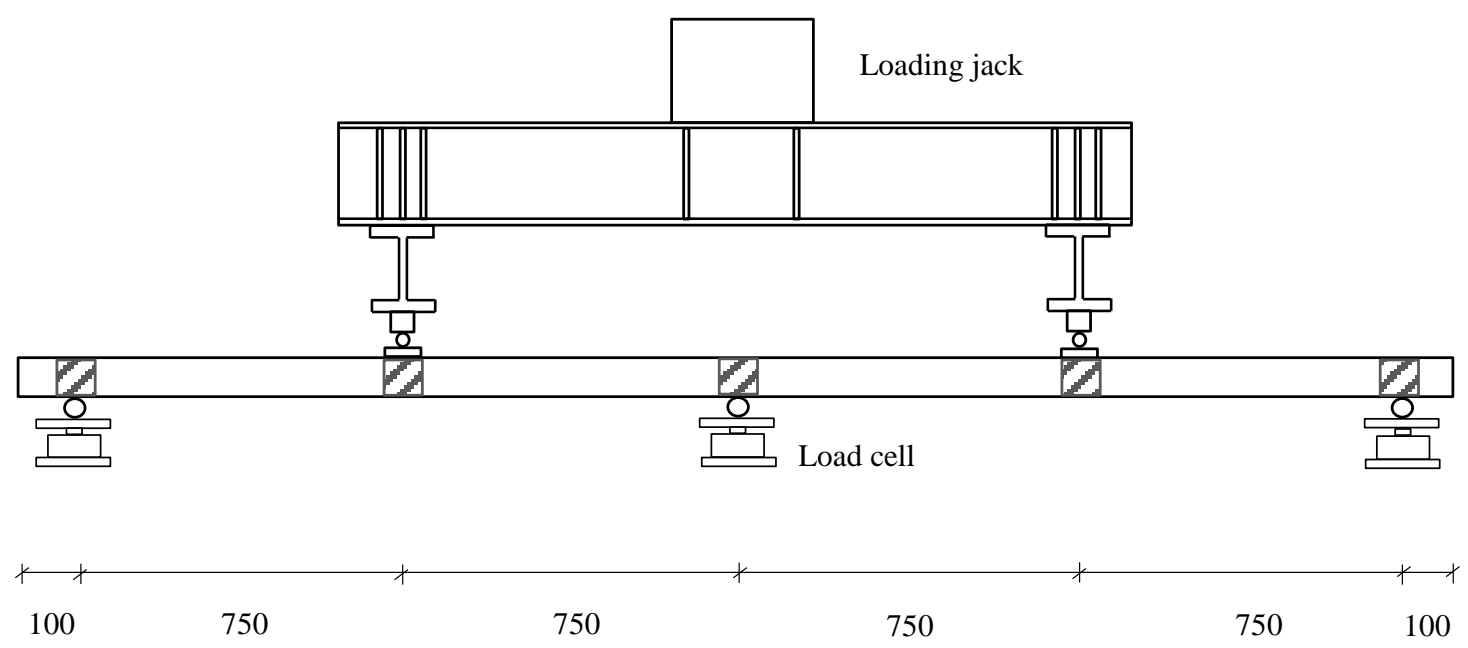

Figure 1. Schematic diagram of the test setup for the continuous beam tests.

Dimensions in $\mathrm{mm}$.

All FE models were performed by the general purpose software Abaqus [13], where the mid-surface of the cross-sections was modelled by four-node shell elements with reduced integration S4R, widely used for cold-formed stainless steel elements, and the nonlinear behaviour was investigated by conducting modified Riks analyses. Loading and boundary conditions adopted in the two span continuous beam tests described in [12] were considered in the models, where regions corresponding to support and loading sections stiffened during the tests by wooden blocks were modelled as kinematic coupling interaction. The bottom faces of the support and loading regions were forced to move as a rigid body referred to their centre points, where the boundary conditions were defined. The longitudinal displacement of the middle support of the two span continuous beams was restrained, while end supports were free to move longitudinally, and loads were introduced as imposed vertical displacements. 
The suitability of the developed FE models for representing the behaviour of ferritic stainless steel continuous tubular beams is demonstrated in Table 1 for RHS and SHS cross-sections bending around their major (Mj) and minor (Mi) axes. The numerical (FE)-to-experimental (exp) ratios of the ultimate loads $\mathrm{F}_{\mathrm{u}, \mathrm{FE}} / \mathrm{F}_{\mathrm{u}, \exp }$ and the corresponding midspan deflections $d_{u, F E} / d_{u, e x p}$ are presented for the continuous beam tests reported in Arrayago and Real [12], together with the mean values and coefficients of variation (COV).

In the model validation, two different material definitions were considered. Initially, the measured material properties of the flat and corner regions of the cross-sections were assigned, where corner material definitions were extended also to the adjacent flat parts by a length equal to two times the thickness of the element, as assumed in Theofanous and Gardner [14]. Residual stresses were not explicitly introduced in the models since according to [15] the stress-strain curves obtained from coupon tests already include the bending residual stresses, and the membrane residual stresses were assumed to be negligible. In addition, the weighted average material properties were also considered in FE models, where the same behaviour was assigned to the entire cross-section in order to evaluate the accuracy of this simplification for further FE analyses. These weighted average material properties were calculated by assigning the value of the corresponding material parameter to the flat or corner regions, which were then weighted according to the area of the considered region compared to the total area of the cross-section. The material parameters describing the behaviour of flat parts, corner parts and weighted average behaviour can be found in the original publication [12]. 
Table 1. Comparison of the FE continuous beam results with test results reported in Arrayago and Real [12].

\begin{tabular}{ccccc}
\hline \multirow{2}{*}{ Specimen } & \multicolumn{2}{c}{$\begin{array}{c}\text { Flat and corner } \\
\text { material }\end{array}$} & \multicolumn{2}{c}{$\begin{array}{c}\text { Ceighted average } \\
\text { material }\end{array}$} \\
\cline { 2 - 5 } & $\mathrm{F}_{\mathrm{u}, \mathrm{FE}} / \mathrm{F}_{\mathrm{u}, \exp }$ & $\mathrm{d}_{\mathrm{u}, \mathrm{FE}} / \mathrm{d}_{\mathrm{u}, \mathrm{exp}}$ & $\mathrm{F}_{\mathrm{u}, \mathrm{FE}} / \mathrm{F}_{\mathrm{u}, \exp }$ & $\mathrm{d}_{\mathrm{u}, \mathrm{FE}} / \mathrm{d}_{\mathrm{u}, \exp }$ \\
\hline $80 \times 80 \times 4$ & 0.97 & 1.01 & 1.00 & 1.39 \\
$60 \times 60 \times 3$ & 1.01 & 0.88 & 0.95 & 1.00 \\
$80 \times 40 \times 4-\mathrm{Mj}$ & 0.99 & 1.07 & 0.99 & 1.26 \\
$80 \times 40 \times 4-\mathrm{Mi}$ & 1.01 & 0.95 & 0.93 & 0.95 \\
$120 \times 80 \times 3-\mathrm{Mj}$ & 0.98 & 1.57 & 0.99 & 1.56 \\
$120 \times 80 \times 3-\mathrm{Mi}$ & 0.99 & 1.03 & 0.98 & 1.10 \\
$70 \times 50 \times 2-\mathrm{Mj}$ & 0.99 & 0.85 & 0.94 & 0.66 \\
$70 \times 50 \times 2-\mathrm{Mi}$ & 1.01 & 0.83 & 0.97 & 0.64 \\
\hline Mean & 0.99 & 1.02 & 0.97 & 1.07 \\
COV & 0.015 & 0.233 & 0.028 & 0.308 \\
\hline
\end{tabular}

Experimental load-midspan deflection curves were also compared to the corresponding FE results considering different constitutive laws in flat and corner regions (FE) and the weighted average material behaviour in the entire cross-section (FE, average material). Figure 2 presents the comparison between experimental and FE results for the $80 \mathrm{x} 40 \mathrm{x} 4-\mathrm{Mj}$ and $60 \times 60 \mathrm{x} 3$ specimens as an example of the typical validation curves obtained for continuous beams. Results in Table 1 and Figure 2 demonstrate that the results derived from the numerical analyses are in good agreement with the considered experimental results for ferritic stainless steel beams when measured material properties are adopted, but also when the weighted average material is considered. Thus, this material definition was considered as a valid simplification and was adopted for the parametric study. 


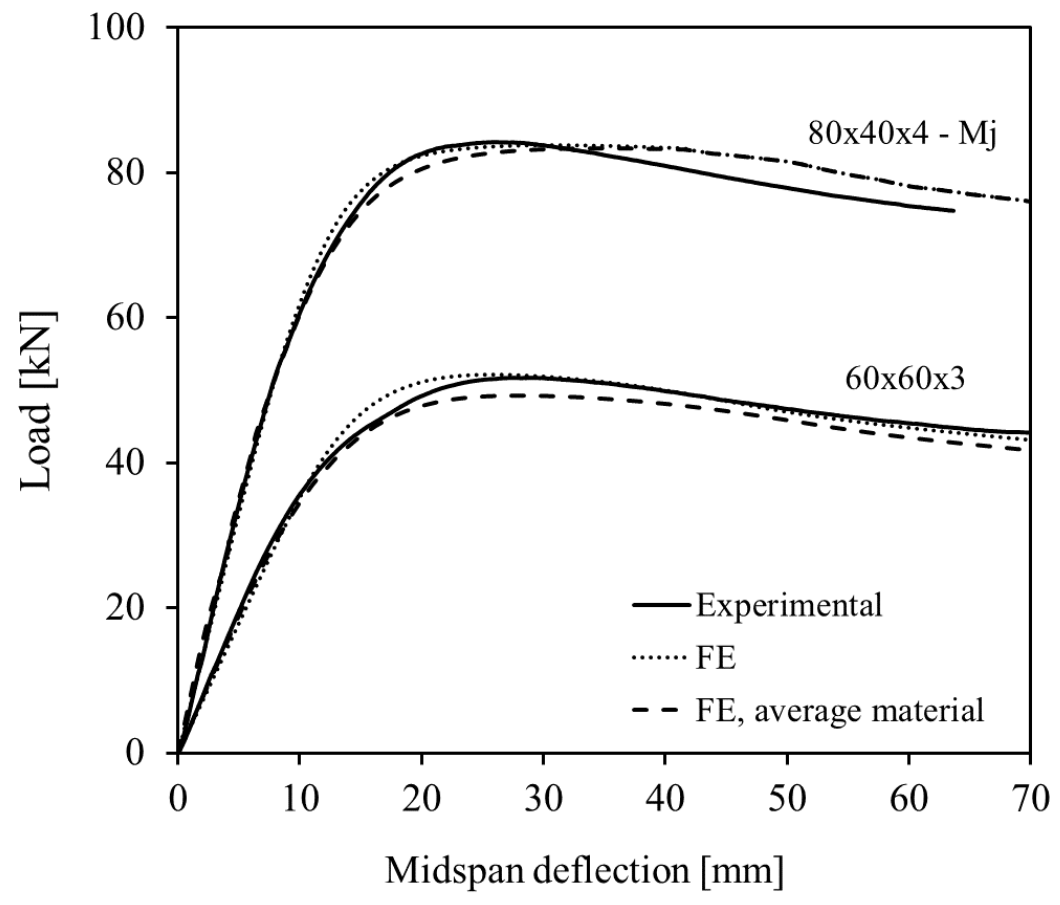

Figure 2. Experimental and FE load-midspan deflection curves for the $80 \mathrm{x} 40 \mathrm{x} 4-\mathrm{Mj}$ and $60 \times 60 \times 3$ specimens.

The applicability of the different plastic design approaches to stainless steel structures was assessed through an extensive FE parametric study through a combination of Phyton and Abaqus tools, where several stocky cross-sections and structural configurations were considered. The parametric study consisted of more than 550 different FE models, including a variety of stocky RHS and SHS Class 1 cross-sections. More slender cross-sections were also included in the analysis in order to identify the transition between Class 1 and Class 2 cross-sections and determine the limit for which global plastic analysis is applicable. Austenitic, ferritic and duplex continuous beams with around 50 different cross-sections were considered in the parametric study, with wall thicknesses ranging between $2 \mathrm{~mm}$ and $6 \mathrm{~mm}$. The outer height of the crosssections ranged from $30 \mathrm{~mm}$ to $80 \mathrm{~mm}$, while widths between $30 \mathrm{~mm}$ and $80 \mathrm{~mm}$ were considered. For each cross-section, several structural configurations requiring different rotation capacities were studied. Two span continuous beams were modelled, with span 
lengths $\mathrm{L}_{\mathrm{s}}$ equal to $1500 \mathrm{~mm}$. The position of the applied load was varied with $\mathrm{L}_{1}$ adopting values around $33 \%, 50 \%, 66 \%$ and $75 \%$ of the considered $\mathrm{L}_{\mathrm{s}}$ (see Figure 3 ).

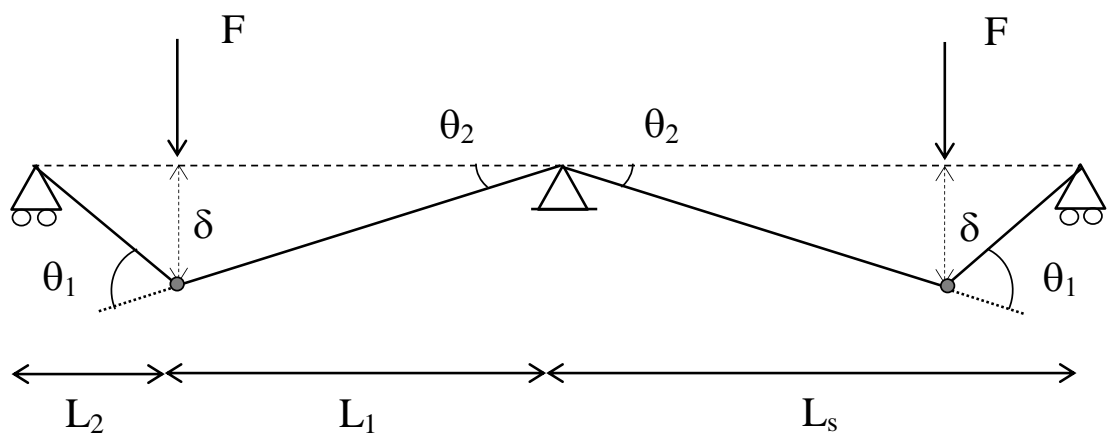

Figure 3. Plastic collapse mechanism for two span continuous beams and symbol definition.

The properties were obtained from the results reported in Arrayago and Real [12] for ferritics, while those used in the parametric studies by Zhao et al. [16] were considered for austenitic and duplex stainless steels and the weighted average material properties were assigned to the entire cross-section. The most relevant material parameters are presented in Table 2 where $\mathrm{E}$ is the Young's modulus, $\sigma_{0.2}$ is the proof stress corresponding to $0.2 \%$ plastic strain, $\sigma_{\mathrm{u}}$ is the tensile strength and $\varepsilon_{\mathrm{u}}$ is the corresponding ultimate strain. Strain hardening exponents $n$ and $m$ are also provided. The stress-strain curves used for the numerical analyses were obtained using the stressstrain curve formulation presented in [17] in combination with the parameters shown in Table 2.

Table 2. Material parameter definition for parametric studies.

\begin{tabular}{ccccccc}
\hline Stainless steel & $\begin{array}{c}\mathrm{E} \\
{[\mathrm{GPa}]}\end{array}$ & $\begin{array}{c}\sigma_{0.2} \\
{[\mathrm{MPa}]}\end{array}$ & $\begin{array}{c}\sigma_{\mathrm{u}} \\
{[\mathrm{MPa}]}\end{array}$ & $\begin{array}{c}\varepsilon_{\mathrm{u}} \\
{[\%]}\end{array}$ & $\mathrm{n}$ & $\mathrm{m}$ \\
\hline Austenitic & 197.8 & 417 & 651 & 35.9 & 5.5 & 3.7 \\
Ferritic & 185.7 & 490 & 533 & 4.8 & 11.0 & 3.2 \\
Duplex & 201.3 & 707 & 874 & 19.1 & 5.6 & 4.9 \\
\hline
\end{tabular}




\section{Design methods for stainless steel indeterminate structures}

\subsection{Design methods based on global elastic analysis}

No rules are given in EN1993-1-4 [1] for plastic global analysis, which should not be used unless there is sufficient experimental evidence to ensure that the assumptions made in the calculations are representative of the actual behaviour of the structure, especially for joints. Thus, the analysis is limited to global elastic analysis, limiting the capacity of stainless steel indeterminate structures to the formation of the first plastic hinge, with no moment redistribution allowed. For the continuous beams analysed in this paper, this is equivalent to establish that the beam fails when the bending capacity of the cross-section is reached at the critical section. This flexural capacity can be predicted following different design methods, such as the expressions codified in EN1993-1-4 [1], the Continuous Strength Method (CSM) provisions and the Direct Strength Method (DSM) approach. According to EN1993-1-4 [1] the flexural resistance of stainless steel beams is determined from Eq. (1), where $\beta_{\mathrm{W}}=1$ is considered for cross-sections classified as Class 1 or 2, for Class 3 sections the elastic bending capacity is determined by considering $\beta_{\mathrm{W}}=\mathrm{W}_{\mathrm{el}} / \mathrm{W}_{\mathrm{pl}}$, and finally, for Class 4 cross-sections, effective properties need to be considered through $\beta_{\mathrm{W}}=\mathrm{W}_{\mathrm{eff}} / \mathrm{W}_{\mathrm{pl}}$, where $\mathrm{W}_{\mathrm{pl}}$ is the plastic modulus, $\mathrm{W}_{\mathrm{el}}$ is the elastic modulus and $\mathrm{W}_{\text {eff }}$ is the effective modulus. In the most recent version of EN1993-1-4 [1] new and more accurate cross-sectional classification limits, proposed by Gardner and Theofanous [18], were adopted. These revised limits were based on austenitic and duplex stainless steel alloys but more recent research works [5,19] concluded that although Class 2 and 3 limits were adequate, the revised Class 1 limit was too optimistic for ferritic stainless steel.

$\mathrm{M}_{\mathrm{c}, \mathrm{Rd}}=\frac{\beta_{\mathrm{W}} \mathrm{W}_{\mathrm{pl}} \cdot \sigma_{0.2}}{\gamma_{\mathrm{M} 0}}$ 
Several research works on cross-sectional resistance demonstrated that including strain hardening effects into bending capacity predictions (considering CSM and DSM design provisions) considerably improves the estimated resistance, particularly for austenitic and duplex stainless steel beams. The CSM is a design method based on cross-section deformation capacity developed for austenitic and duplex stainless grades by Afshan and Gardner [4] and then adapted to the less ductile ferritic grades by Bock et al. [5]. The method is based on the calculation of the maximum strain $\varepsilon_{\mathrm{CSM}}$ that a cross-section can reach, evaluated in terms of its relative slenderness $\lambda_{1}$ from the CSM base curve and a simplified bilinear material model that includes strain hardening effects. The bending capacity according to the CSM $M_{\mathrm{CSM}}$ can be calculated from Eq. (2), where $\mathrm{M}_{\mathrm{pl}}$ is the plastic bending moment capacity of the cross-section, $\mathrm{E}_{\mathrm{sh}}$ is the strain hardening modulus and E is the Young's modulus.

$$
\frac{\mathrm{M}_{\mathrm{CSM}}}{\mathrm{M}_{\mathrm{pl}}}=1+\frac{\mathrm{E}_{\mathrm{sh}}}{\mathrm{E}} \frac{\mathrm{W}_{\mathrm{el}}}{\mathrm{W}_{\mathrm{pl}}}\left(\frac{\varepsilon_{\mathrm{CSM}}}{\varepsilon_{\mathrm{y}}}-1\right)-\left(1-\frac{\mathrm{W}_{\mathrm{el}}}{\mathrm{W}_{\mathrm{pl}}}\right) \cdot\left(\frac{\varepsilon_{\mathrm{CSM}}}{\varepsilon_{\mathrm{y}}}\right)^{-2}
$$

Alternatively, the DSM, developed by Schafer and Pekoz [20], allows the consideration of local buckling effects in an easy manner through the use of strength curves and can also account for strain hardening effects by using the modified DSM approach proposed by Rossi and Rasmussen [6] and Arrayago et al. [7], as given in Eq. (3). The method is also based on the local cross-section slenderness $\lambda_{1}$ and considers the inelastic reserve strength $\mathrm{M}_{\mathrm{n}}$ obtained from Eq. (4) as a function of the maximum compressive strain $\mathrm{C}_{\mathrm{y}} \cdot \varepsilon_{\mathrm{y}}$, where $\mathrm{C}_{\mathrm{y}}$ is the compression strain factor calculated as a direct function of the cross-sectional slenderness $\lambda_{1}$. Arrayago et al. [7] demonstrated that the $\mathrm{C}_{\mathrm{y}}$ provision given in "Procedure II" of AS/NZS4673 [2] and SEI/ASCE 8-02 [3], as shown in Eq. (5), provides excellent results for stainless steel RHS and SHS beams. 


$$
\begin{aligned}
& \frac{\mathrm{M}_{\mathrm{DSM}}}{\mathrm{M}_{\mathrm{n}}}=\left\{\begin{array}{c}
1+\left(1-1.29 \lambda_{1}\right)\left(\frac{\sigma_{\mathrm{u}}}{\sigma_{0.2}}-1\right) \text { for } \lambda_{1} \leq 0.776 \\
\frac{1}{\lambda_{1}^{0.8}}-\frac{0.15}{\lambda_{1}^{1.6}} \text { for } \lambda_{1} \geq 0.776
\end{array}\right. \\
& \mathrm{M}_{\mathrm{n}}=\mathrm{M}_{\mathrm{y}}+\left(\mathrm{M}_{\mathrm{pl}}-\mathrm{M}_{\mathrm{y}}\right)\left[1-\frac{1}{\mathrm{C}_{\mathrm{y}}^{2}}\right] \\
& \mathrm{C}_{\mathrm{y}}=\left\{\begin{array}{c}
\lambda_{1} \leq 0.58 \\
3-2\left(\frac{\lambda_{1}-0.58}{0.196}\right) \begin{array}{c}
3 \\
1 \\
1
\end{array} \lambda_{1} \leq 0.776 \\
\lambda_{1} \geq 0.776
\end{array}\right.
\end{aligned}
$$

\subsection{Design methods based on global plastic analysis}

\subsubsection{Traditional global plastic design}

European standard for carbon steel structures EN1993-1-1 [8] allows the adoption of the traditional global plastic design method based on the formation of plastic hinges for those structures with cross-sections stocky enough by considering a plastic collapse mechanism similar to that shown in Figure 3 and a rigid-plastic material response. In this figure $L_{s}$ corresponds to the considered span length, while $L_{1}$ is the distance between the applied load and the internal support and $\mathrm{L}_{2}=\mathrm{L}_{\mathrm{S}}-\mathrm{L}_{1}$, as previously defined in the parametric studies. The collapse load is calculated through the virtual work principle, where the external work done by the applied loads $F_{k}$ acting through virtual displacements $\delta_{\mathrm{k}}$ is equated to the internal work resulting from the hinge rotations $\theta_{\mathrm{i}}$ as given in Eq. (6).

$\sum_{\mathrm{k}} \mathrm{F}_{\mathrm{k}} \delta_{\mathrm{k}}=\sum_{\mathrm{i}} \mathrm{M}_{\mathrm{i}} \theta_{\mathrm{i}}$

Plastic design is limited to those cross-sections showing sufficient rotation capacity to allow moment redistribution in the structure. EN1993-1-1 [8] and EN1993-1-4 [1] consider these cross-sections as Class 1. 


\subsubsection{CSM for indeterminate structures}

According to Theofanous et al. [10] and Arrayago and Real [12], the traditional plastic design approach provides conservative strength predictions for continuous beams showing low cross-section slendernesses, since only the yielding of the cross-sections is considered without accounting for strain hardening effects. On these bases, Gardner et al. [9] developed an alternative approach for carbon steel indeterminate structures based on CSM provisions, whose applicability was assessed by [10] for different stainless steel grades. Su et al. [21] presented a detailed discussion on the CSM plastic design approach for five-point bending beams and studied the applicability of the method to indeterminate aluminum alloy structures.

The CSM for indeterminate structures is a design method based on global plastic design, where bending moment capacities from the CSM bending resistance equations (allowing for strain hardening) are assigned to the different plastic hinges instead of the traditional plastic moment capacities $\mathrm{M}_{\mathrm{pl}}$. The method assigns the full CSM crosssectional resistance to the critical plastic hinge and allows a degree of strain hardening for the rest of the hinges. The critical hinge is identified as that showing the largest rotation capacity demand relative to the deformation capacity of the cross-section. The rotation demand of each hinge is calculated using Eq. (7), where $\theta_{\mathrm{i}}$ is the rotation derived from kinematic considerations for the collapse mechanism considered, $h_{i}$ is the section height at the considered location and $\left(\varepsilon_{\mathrm{CSM}} / \varepsilon_{\mathrm{y}}\right)_{\mathrm{i}}$ is the corresponding normalized CSM strain ratio at the $i^{\text {th }}$ hinge. Once the critical hinge is identified, the rest of relative rotation demands can be obtained from Eq. (8), and the corresponding bending capacities are calculated from Eq. (2). 


$$
\begin{aligned}
& \alpha_{i}=\frac{\theta_{i} \cdot h_{i}}{\left(\varepsilon_{\mathrm{CSM}} / \varepsilon_{\mathrm{y}}\right)_{\mathrm{i}}} \\
& \left(\frac{\varepsilon_{\mathrm{CSM}}}{\varepsilon_{\mathrm{y}}}\right)_{\mathrm{i}}=\frac{\alpha_{\mathrm{i}}}{\alpha_{\text {crit }}}\left(\frac{\varepsilon_{\mathrm{CSM}}}{\varepsilon_{\mathrm{y}}}\right)_{\text {crit }} \leq\left(\frac{\varepsilon_{\mathrm{CSM}}}{\varepsilon_{\mathrm{y}}}\right)_{\mathrm{i}, \text { limit }}
\end{aligned}
$$

According to this method, the full deformation capacity is exploited for the first plastic hinge $\mathrm{M}_{\mathrm{CSM}}$, while for the subsequent plastic hinges deformations are reduced in proportion to the plastic hinge rotation ratios through the calculated $\varepsilon_{\mathrm{CSM}}$ values. The limits designated in Eq. (8) represent the CSM applicability limits stated in [4,5] due to material ductility requirements in [8] and to avoid overpredictions for the adopted bilinear material model. Finally, the collapse load of the structure can be calculated through the virtual work principle as in conventional plastic design but adopting the predicted bending capacities at each plastic hinge instead of the traditional plastic moment capacity $\mathrm{M}_{\mathrm{pl}}$.

From Eq. (7), the relative rotation demand $\alpha_{i}$ of each hinge is proportional to the absolute rotation demands $\theta_{\mathrm{i}}$ shown in Figure 3, since the cross-section height $\mathrm{h}_{\mathrm{i}}$ and basic $\left(\varepsilon_{\mathrm{CSM}} / \varepsilon_{\mathrm{y}}\right)_{\mathrm{i}}$ ratios are constant along the member length for the analysed specimens. Therefore, the capacities of the plastic hinges with reduced deformation can be determined from the absolute rotation demands $\theta_{\mathrm{i}}$. For those loading configurations where the distance between the internal support and the load is lower than the half of the span $\mathrm{L}_{1} \leq \mathrm{L}_{\mathrm{s}} / 2$, the critical hinge is that formed in the support section, while for $\mathrm{L}_{1} \geq \mathrm{L}_{\mathrm{s}} / 2$ configurations the critical hinge is formed in the loading section. For $\mathrm{L}_{1}=\mathrm{L}_{\mathrm{s}} / 2$ all plastic hinges require the same relative rotation demands.

Sufficient deformation capacity for moment redistribution to occur is usually guaranteed by ensuring a rotation capacity of $R \geq 3$. The rotation capacity, graphically 
defined in Figure 4, is determined from $\mathrm{R}=\kappa_{\mathrm{u}} / \kappa_{\mathrm{pl}}-1$, where $\kappa_{\mathrm{u}}$ is the curvature corresponding to the ultimate load and $\kappa_{\mathrm{pl}}$ is the elastic curvature corresponding to the plastic moment capacity $\mathrm{M}_{\mathrm{pl}}$ in the ascending branch, defined as $\kappa_{\mathrm{pl}}=\mathrm{M}_{\mathrm{pl}} / \mathrm{EI}$. E is the Young's modulus and I is the second moment of inertia of the cross-section.

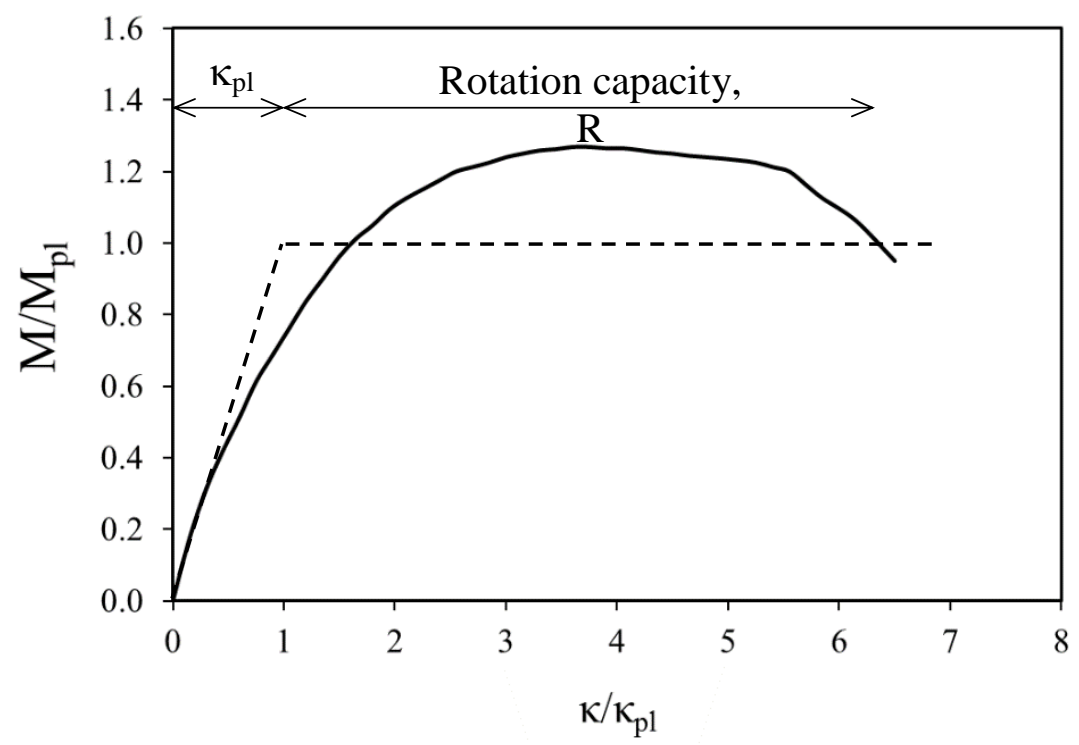

Figure 4. Graphic definition of the rotation capacity, R.

It is worth mentioning that the revised Class 1 limit was adopted on the basis of the rotation capacity of simply supported beams, without considering the performance of these cross-sections as indeterminate structures. In addition, as highlighted by different authors $[10,12]$, the relevance of this $\mathrm{R} \geq 3$ criterion is less clear than for carbon steel and should be revised when considering stainless steels, since the plastic moment capacity of these cross-sections is not clear. Gardner et al. [9] proposed a new criterion based on deformation capacity in order to guarantee that a cross-section is capable of moment redistribution in indeterminate structures with a minimum value of $\varepsilon_{\mathrm{CSM}} / \varepsilon_{\mathrm{y}} \geq 3$ for I-sections and 3.6 for box sections, where $\varepsilon_{\mathrm{CSM}}$ is the CSM strain and $\varepsilon_{\mathrm{y}}$ is the yielding strain. This limit corresponds to the $\varepsilon_{\mathrm{CSM}} / \varepsilon_{\mathrm{y}}$ ratio at which the calculated CSM bending capacity $\mathrm{M}_{\mathrm{CSM}}$ equals the plastic bending moment $\mathrm{M}_{\mathrm{pl}}$, which occurs at a local 
slenderness $\lambda_{1}=0.47$ according to the CSM base curve. Note that the revised Class 1 limit codified in EN1993-1-4 [1] is $\mathrm{c} / \mathrm{t} \varepsilon=33$, which corresponds to a local slenderness of $\lambda_{1}=0.58$, while the former Class 1 limit $(\mathrm{c} / \mathrm{t} \varepsilon=25.7)$ was equivalent to $\lambda_{1}=0.45$, closer to the limit proposed for the CSM method.

\section{Assessment of design methods}

The different design methods described in the previous section are evaluated herein by comparing the experimental and numerical ultimate strengths with the strength predictions for the considered methods. In addition to this evaluation, the reliability of the approaches is also checked through relevant statistical analyses.

\subsection{Assessment of design methods based on global elastic analysis}

The assessment of design methods based on global elastic analysis is reported in Table 3 for austenitic, ferritic and duplex stainless steel continuous beams. Results corresponding to the comparison of experimental and FE strengths derived from the parametric study with the loads at which the first plastic hinge is formed $F_{h 1}$ are presented. Since the revised Class 1 limit included in the latest version of EN1993-1-4 [1] $(\mathrm{c} / \mathrm{t} \varepsilon=33)$ was found to be inaccurate for some stainless steel grades [5,19] and the applicability limit provided in the CSM method for indeterminate structures $(\mathrm{c} / \mathrm{t} \varepsilon=26.7)$ is closer to the former codified Class 1 limit $(\mathrm{c} / \mathrm{t} \varepsilon=25.7)$, both Class 1 limits have been considered in the assessment. For each stainless steel grade the mean values and coefficients of variation of the predicted-to-experimental (or $\mathrm{FE}$ ) ratios $\mathrm{F}_{\mathrm{h} 1 \text {,pred }} / \mathrm{F}_{\mathrm{u}}$ are provided. $F_{h 1, E N, p r e v}$ stands for the limits provided in the previous version of EN1993-1-4 [1], while $\mathrm{F}_{\mathrm{h} 1 \mathrm{EN}}$ corresponds to the bending capacity predictions according to the codified revised classification limits in EN1993-1-4 [1]. $\mathrm{F}_{\mathrm{h} 1, \mathrm{CSM}}$ and $\mathrm{F}_{\mathrm{h} 1, \mathrm{DSM}}$ correspond 
to the bending capacities calculated according to the CSM and the DSM provisions described in previous section, respectively.

Table 3. Assessment of design methods based on global elastic analysis.

\begin{tabular}{cccccc}
\hline \multirow{2}{*}{ Grade } & & $\mathrm{F}_{\mathrm{h} 1, \mathrm{EN}, \text { prev }} / \mathrm{F}_{\mathrm{u}}$ & $\mathrm{F}_{\mathrm{h} 1, \mathrm{EN}} / \mathrm{F}_{\mathrm{u}}$ & $\mathrm{F}_{\mathrm{h} 1, \mathrm{CSM}} / \mathrm{F}_{\mathrm{u}}$ & $\mathrm{F}_{\mathrm{h} 1, \mathrm{DSM}} / \mathrm{F}_{\mathrm{u}}$ \\
\hline \multirow{2}{*}{ Austenitic } & Mean & 0.63 & 0.64 & 0.74 & 0.83 \\
& COV & 0.134 & 0.139 & 0.106 & 0.122 \\
\hline \multirow{2}{*}{ Ferritic } & Mean & 0.74 & 0.76 & 0.79 & 0.78 \\
& COV & 0.107 & 0.131 & 0.121 & 0.125 \\
\hline \multirow{2}{*}{ Duplex } & Mean & 0.69 & 0.70 & 0.74 & 0.77 \\
& COV & 0.106 & 0.149 & 0.101 & 0.123 \\
\hline \multirow{2}{*}{ All } & Mean & 0.69 & 0.70 & 0.76 & 0.79 \\
& COV & 0.132 & 0.157 & 0.114 & 0.127 \\
\hline
\end{tabular}

According to the results reported in Table 3 the ultimate load predictions tend to be highly conservative and scattered when design methods based on global elastic analysis are considered, regardless of the adopted cross-sectional bending moment resistance. However, higher $F_{h 1, p r e d} / F_{u}$ ratios are observed for the approaches that consider strain hardening effects, such as the CSM and the DSM. Since most of the analysed crosssections show considerably low cross-section slendernesses, this conservatism can be partly attributed to strain hardening effects but mainly to the bending moment redistribution capacity of the studied beams. As it can be observed, the most conservative results are obtained for austenitic and duplex stainless steel beams, followed by ferritic specimens. This is in line with the typical stress-strain diagrams shown by these grades, where austenitics exhibit the highest $\sigma_{\mathrm{u}} / \sigma_{0.2}$ ratios while strain hardening effects are less relevant for ferritics. Thus, it is essential for an efficient use of stainless steel structures to provide design guidance where both strain hardening and bending moment redistribution are considered.

\subsection{Assessment of design methods based on global plastic analysis}

The results presented in the previous section for stainless steel RHS and SHS continuous beams with stocky cross-sections demonstrated that the adoption of design 
methods based on global elastic analyses, as currently codified in EN1993-1-4 [1], provides overly conservative strength predictions. As demonstrated above, including strain hardening effects in the formulation improves the obtained results but they are still overly conservative, which indicates that bending moment redistribution also needs to be accounted for in the design of stainless steel structures.

Figure 5 presents the assessment of the traditional global plastic design method for the different stainless steel grades analysed by plotting the $F_{\text {coll }} / F_{u}$ ratios against the corresponding local slendernesses determined from CUFSM (Schafer and Ádány [22]) calculations, where $\mathrm{F}_{\text {coll }}$ is the predicted capacity of the beam attending to plastic design and $\mathrm{F}_{\mathrm{u}}$ is the experimental (or FE) beam strength. Limiting slendernesses corresponding to the Class 1 limit previously given in EN1993-1-4 $\left(\lambda_{1, \mathrm{EN}, \mathrm{prev}}=0.45\right)$ and the revised limit codified in EN1993-1-4 $\left(\lambda_{1, \mathrm{EN}}=0.58\right)$ are also shown for comparison.

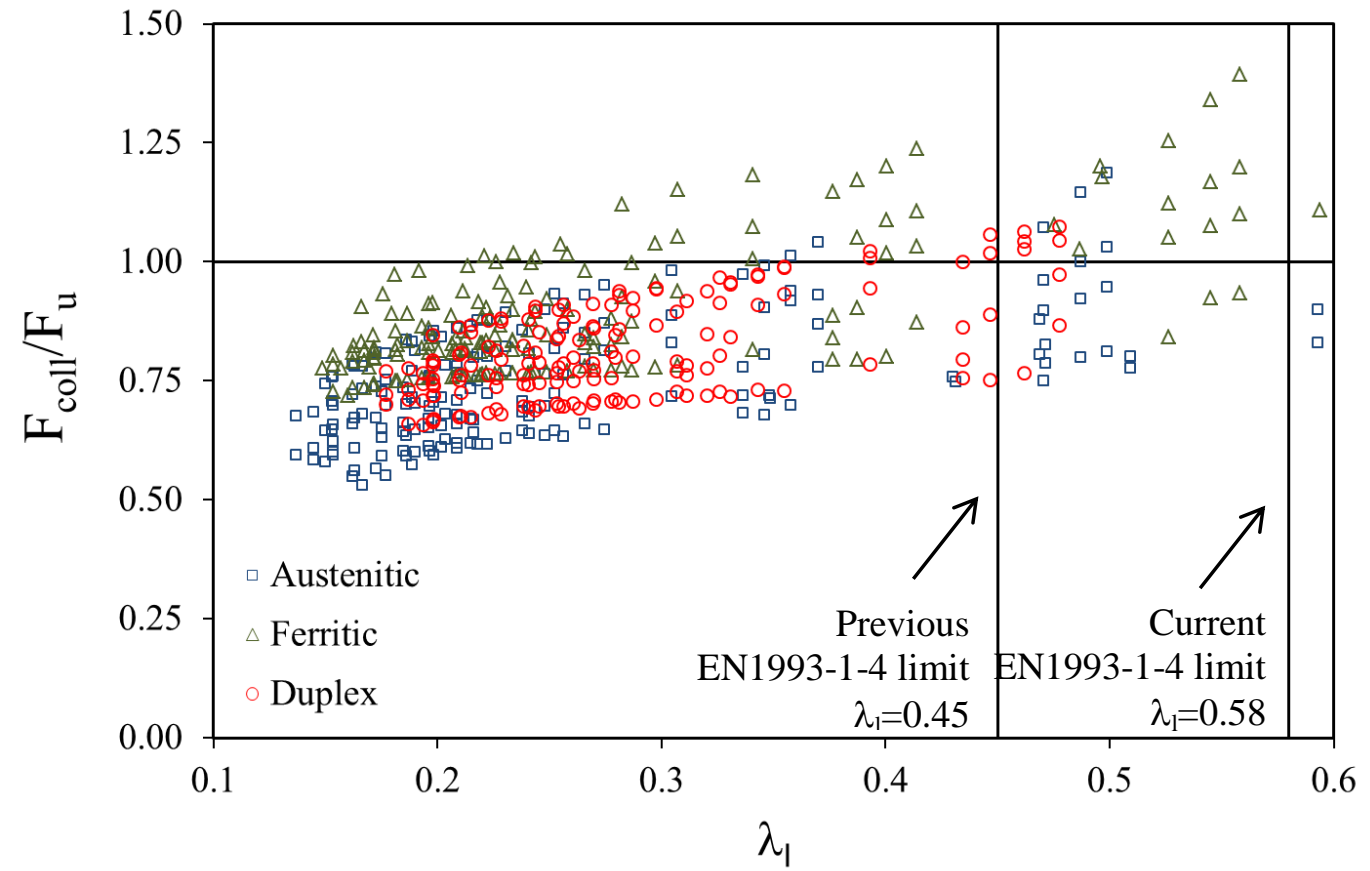

Figure 5. Assessment of the traditional plastic design method for different stainless steel grades.

As it is appreciated in Figure 5, the capacity of the most slender specimens is overpredicted when global plastic design is considered, while the predictions get more 
accurate for cross-sections showing an intermediate slenderness. For the stockiest crosssections, where the effect of strain hardening is more influential, the consideration of an elastic-perfectly plastic material results in overconservative predictions. A similar behaviour is observed for all the analysed materials, although predictions for austenitic stainless steel continuous beams are found to be the most conservative, followed by duplex and ferritic grades. However, Figure 5 shows that the strength of several ferritic specimens with low local slenderness, and which correspond to loading configurations with $\mathrm{L}_{1} / \mathrm{L}=0.33$, is overestimated when traditional plastic design is considered. This is caused by the less ductile behaviour typically exhibited by these stainless steel grades, although the statistical analyses presented bellow will overcome these few unsafe results.

As it can be appreciated in this figure, a considerable scatter is observed for the data corresponding to the stainless steel alloys considered, which is more evident as crosssections become more slender. This scatter is attributed to the effect of different instabilities caused by the concentrated forces introduced at supports and loading sections, such as web crippling. Although these instabilities are accounted for in the FE models, the predicted capacities according to global plastic methods $F_{\text {coll }}$ do not consider them. This results in higher and more scattered $F_{\text {coll }} / F_{u}$ ratios for cross-sections showing increasing slenderness, since these instabilities are more relevant for more slender sections. A similar behaviour can be also observed in Figure 6 below.

Figure 6 presents the predicted capacities calculated using the CSM for indeterminate structures $\mathrm{F}_{\text {coll,CSM }}$ normalized by the experimental and numerical strengths for austenitic, ferritic and duplex stainless steel continuous beams. Results are again plotted against the corresponding local slenderness determined from CUFSM calculations. Only results corresponding to local slendernesses lower than $\lambda_{1} \leq 0.47$ are considered in 
the analysis, since for more slender cross-sections the CSM would predict bending moments between the elastic and plastic bending capacities and the calculated collapse loads would not be comparable with traditional design plastic design results.

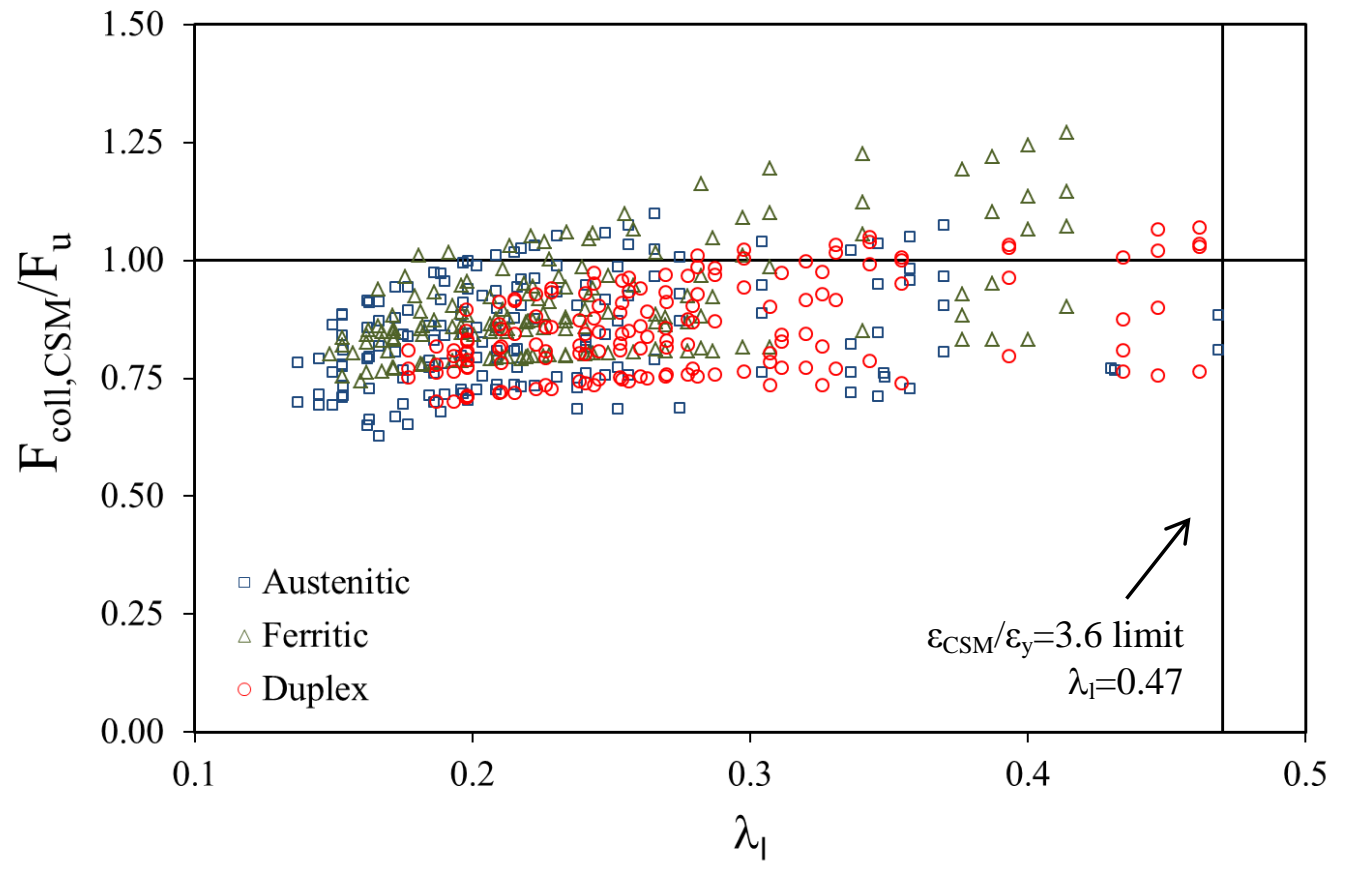

Figure 6. Assessment of the CSM for indeterminate structures for different stainless steel grades.

The comparison between Figures 5 and 6 demonstrates that the strength prediction of stainless steel continuous beams is clearly improved when strain hardening effects are incorporated to the strength calculation along with the redistribution of bending moments. This improvement is more evident for austenitic specimens, while only slight modifications are appreciated for ferritics, stainless steel grades showing lowest $\sigma_{\mathrm{u}} / \sigma_{0.2}$ ratios.

The numerical assessment and comparison of the analysed plastic design methods is presented in Table 4. The mean values and coefficients of variation of the predicted-toexperimental (or FE) ratios are reported for the different design approaches and stainless steel grades. The assessment of the traditional plastic design is investigated for those cross-sections classified as Class 1 according to the two classification limits considered, 
the Class 1 limit given in the previous version of EN1993-1-4 and that currently codified in EN1993-1-4 [1], denoted as $\mathrm{F}_{\text {coll,EN,prev }} / \mathrm{F}_{\mathrm{u}}$ and $\mathrm{F}_{\text {coll,EN }} / \mathrm{F}_{\mathrm{u}}$ respectively. Results corresponding to the CSM for indeterminate structures $\mathrm{F}_{\text {coll, CSM }} / \mathrm{F}_{\mathrm{u}}$ showing local slendernesses lower than $\lambda_{1} \leq 0.47$ are also reported.

Table 4. Assessment of design methods based on global plastic design.

\begin{tabular}{ccccc}
\hline \multirow{2}{*}{ Grade } & & $\mathrm{F}_{\text {coll,EN,prev }} / \mathrm{F}_{\mathrm{u}}$ & $\mathrm{F}_{\text {coll,EN }} / \mathrm{F}_{\mathrm{u}}$ & $\mathrm{F}_{\text {coll,CSM }} / \mathrm{F}_{\mathrm{u}}$ \\
\hline \multirow{2}{*}{ Austenitic } & Mean & 0.75 & 0.75 & 0.84 \\
& COV & 0.169 & 0.166 & 0.132 \\
\hline \multirow{2}{*}{ Ferritic } & Mean & 0.87 & 0.89 & 0.90 \\
& COV & 0.128 & 0.153 & 0.126 \\
\hline \multirow{2}{*}{ Duplex } & Mean & 0.81 & 0.83 & 0.86 \\
& COV & 0.126 & 0.155 & 0.113 \\
\hline \multirow{2}{*}{ All } & Mean & 0.81 & 0.82 & 0.87 \\
& COV & 0.153 & 0.172 & 0.127 \\
\hline
\end{tabular}

According to the results reported in Table 4, it is evident that allowing for plastic design in stainless steel structures considerably improves the ultimate capacity prediction of continuous beams. However, and as mentioned previously, the adoption of an elasticperfectly plastic material response results in still considerably conservative capacity predictions for stainless steel grades characterized by high strain hardening effects. Including these effects together with global plastic design methods in design approaches provides much more accurate capacity predictions, as shown for the CSM in Table 4. Based on the test and FE data analysed in this paper, it is shown that the CSM for indeterminate structures, which allows for both strain hardening and moment redistribution, is capable of more accurately predicting the collapse load of stainless steel indeterminate beams than the traditional plastic analysis approach.

\subsection{Reliability analysis of design methods based on global plastic analysis}

Although results reported in Table 4 provide mean $F_{\text {pred }} / F_{u}$ ratios lower than unity, the capacity of several specimens is over-predicted, as highlighted in Figures 5 and 6, particularly for loading configurations with low $\mathrm{L}_{1} / \mathrm{L}$ ratios $\left(\mathrm{L}_{1} / \mathrm{L}=0.33\right)$. Hence, the 
reliability of these design approaches is assessed by conducting the relevant statistical analyses for the traditional global plastic design approach (considering both crosssection classification limits) and the CSM approach for indeterminate structures.

The validation has been derived according to EN1990, Annex D [23] specifications, following the steps described in Tankova et al. [24] and using the statistical parameters corresponding to the material and geometrical variations reported by Afshan et al. [25] for the different stainless steel alloys. The considered over-strength factors for the material yield strengths $\sigma_{0.2 \text {,mean }} / \sigma_{0.2 \text {,min }}$ are 1.3 for austenitic stainless steel, 1.2 for ferritics and 1.1 for duplex and lean duplex grades, with COVs equal to $0.060,0.045$ and 0.030 respectively. $\sigma_{0.2 \text {,mean }}$ corresponds to the mean value produced by stainless steel manufacturers and $\sigma_{0.2 \text {,min }}$ to the minimum specified value in EN10088-4 [26]. The mean-to-nominal ratio and $\mathrm{COV}$ of the geometric properties were taken as 1.0 and 0.050, respectively. The variability due to FE modelling was also included in the analysis, since some deviation between tests and the modelled reality usually occurs. For this, the coefficient of variation $\mathrm{V}_{\mathrm{FE}}=0.015$ was included in the coefficient of variation $\mathrm{V}_{\mathrm{rt}}$ that accounts for the sensitivity of the resistance function to the variability of the basic input parameters.

A summary of the most relevant statistical parameters is presented in Table 5, where b is the mean value of the correction factor, $V_{\delta}$ is the coefficient of variation of the errors of each approach relative to the experimental results and $V_{r}$ is the combined coefficient of variation. Finally, $\gamma_{\mathrm{M} 0}$ corresponds to the calculated partial safety factor for each stainless steel grade. 
Table 5. Summary of the reliability analysis results for current global plastic design methods for continuous beams.

\begin{tabular}{cccccc}
\hline & Grade & $\mathrm{b}$ & $\mathrm{V}_{\delta}$ & $\mathrm{V}_{\mathrm{r}}$ & $\gamma_{\mathrm{M} 0}$ \\
\hline Traditional plastic & Austenitic & 1.336 & 0.164 & 0.182 & 0.95 \\
design for the previous & Ferritic & 1.144 & 0.121 & 0.140 & 1.08 \\
EN1993-1-4 limit & Duplex & 1.229 & 0.123 & 0.138 & 1.05 \\
\hline Traditional plastic & Austenitic & 1.318 & 0.162 & 0.181 & 0.96 \\
design for the & Ferritic & 1.085 & 0.143 & 0.159 & 1.25 \\
EN1993-1-4 limit & Duplex & 1.196 & 0.147 & 0.159 & 1.16 \\
\hline \multirow{2}{*}{ CSM-based plastic } & Austenitic & 1.175 & 0.131 & 0.154 & 0.95 \\
design & Ferritic & 1.097 & 0.120 & 0.139 & 1.10 \\
& Duplex & 1.155 & 0.112 & 0.127 & 1.09 \\
\hline
\end{tabular}

According to the results reported in Table 5 and the partial safety factor $\gamma_{\mathrm{M} 0}$ currently provided in EN1993-1-4 [1] for cross-sectional resistance, equal to 1.10, the traditional plastic design approach can be safely applied for all stainless steel grades if the Class 1 limit given in the previous version of EN1993-1-4 [1] is considered. Same conclusions can be derived for the CSM approach for indeterminate structures since the calculated $\gamma_{\mathrm{M} 0}$ values also lay below the provided $\gamma_{\mathrm{M} 0}=1.10$ value. However, according to the partial safety factors $\gamma_{\mathrm{M} 0}$ reported in Table 5 for the traditional plastic design approach considering the revised Class 1 limit currently codified in EN1993-1-4 [1], strength predictions are too optimistic for the considered ferritic and duplex stainless steel grades. Consequently, the limit provided for Class 1 cross-sections cannot be safely used according to the analysed data.

\section{New DSM approach for global plastic design}

The design approaches based on global plastic design assessed in the previous section, particularly the CSM for indeterminate structures, have been found to be an excellent alternative for the design of stainless steel continuous beams, since strain hardening effects and bending moment redistribution are considered. The approaches have also been demonstrated to satisfy the reliability requirements for the safe application of the CSM for indeterminate structures and the traditional plastic analysis approach for the 
EN1993-1-4 [1] Class 1 limit. However, a new Direct Strength Method (DSM) approach for stainless steel indeterminate structures is proposed in section 5.1 following a similar procedure to that used in the CSM approach for indeterminate structures. This new DSM proposal for global plastic design is based on the alternative DSM design expressions proposed by Arrayago et al. [7] for flexural capacity.

\subsection{Development and assessment of the new DSM approach for plastic design}

The CSM method assigns, as described in the previous section, the full CSM deformation capacity to the critical hinge, and deformations are reduced for subsequent plastic hinges in proportion to the relative rotation ratios. Thus, the full CSM bending moment capacity is assigned to the first plastic hinge while reduced capacities based on the absolute rotation demands $\theta_{\mathrm{i}}$ are assigned to the rest. The same principle can be adopted for a modified DSM approach for indeterminate structures, where the full DSM bending capacity $\mathrm{M}_{\mathrm{DSM}}$ is assigned to the critical hinge and reduced capacities are adopted for the subsequent plastic hinges. Since the analysed specimens present a constant cross-section along the length, these reductions can be determined from the absolute rotation demands $\theta_{\mathrm{i}}$. The DSM approach for stainless steel RHS and SHS beams proposed in Arrayago et al. [7] is based on the cross-section slenderness of the specimen, from which the bending capacity $\mathrm{M}_{\mathrm{DSM}}$ is calculated. In the proposed method, the bending resistance associated to each plastic hinge is determined from an equivalent local slenderness $\lambda_{1}^{*}$ determined from Eq. (9), being $\theta_{\text {crit }}$ the absolute rotation demand of the critical hinge.

$\lambda_{l, i}^{*}=\frac{\theta_{\text {crit }}}{\theta_{\mathrm{i}}} \lambda_{1}$

Once the equivalent local slenderness $\lambda_{1}^{*}$ of each particular hinge is determined, the corresponding bending capacity is calculated from the equations proposed in [7] and the 
collapse load is calculated through the virtual work principle. In order to verify that the member presents sufficient deformation capacity, a criterion based on deformation capacity is also proposed. For simplicity, and considering the results from previous sections, the c/ct limit provided in the previous version of EN1993-1-4 [1] for Class 1 cross-sections has been adopted, which corresponds to a slenderness equal to $\lambda_{1} \leq 0.45$ for internal elements in pure compression. Note again that this limit is very similar to that adopted by the CSM approach for indeterminate structures.

The assessment to the proposed approach is reported in Table 6, where mean values and COVs of the predicted-to-experimental (or FE) ratios are presented. Results indicate that, as strain hardening effects and bending moment redistribution are considered, the adapted DSM approach for continuous beams provides excellent strength predictions for all stainless steel grades. Although mean values are slightly higher than those reported in Table 4 for the CSM, particularly for austenitic specimens, the accuracy of both methods is found to be essentially the same.

Table 6. Assessment of the proposed DSM design approach.

\begin{tabular}{ccc} 
Grade & & $\mathrm{F}_{\text {coll,DSM }} / \mathrm{F}_{\mathrm{u}}$ \\
\hline \multirow{2}{*}{ Austenitic } & Mean & 0.94 \\
& COV & 0.118 \\
\hline \multirow{2}{*}{ Ferritic } & Mean & 0.88 \\
& COV & 0.109 \\
\hline \multirow{2}{*}{ Duplex } & Mean & 0.87 \\
& COV & 0.100 \\
\hline \multirow{2}{*}{ All } & Mean & 0.89 \\
& COV & 0.115 \\
\hline
\end{tabular}

Figure 7 presents the normalized predicted capacities calculated using the proposed DSM design approach $\mathrm{F}_{\text {coll,DSM }} / \mathrm{F}_{\mathrm{u}}$ for austenitic, ferritic and duplex stainless steel continuous beams, plotted against the corresponding local slenderness, together with the proposed $\lambda_{1} \leq 0.45$ limit. The comparison of these results with those presented in Figures 5 and 6 highlight the conclusions already presented in Table 6 . It can be 
observed that strength predictions are more accurate since the strain hardening effects and bending moment redistribution are incorporated and although results are similar to those shown in Figure 6, the lower and more uniform scatter is observed for the analysed local slenderness range.

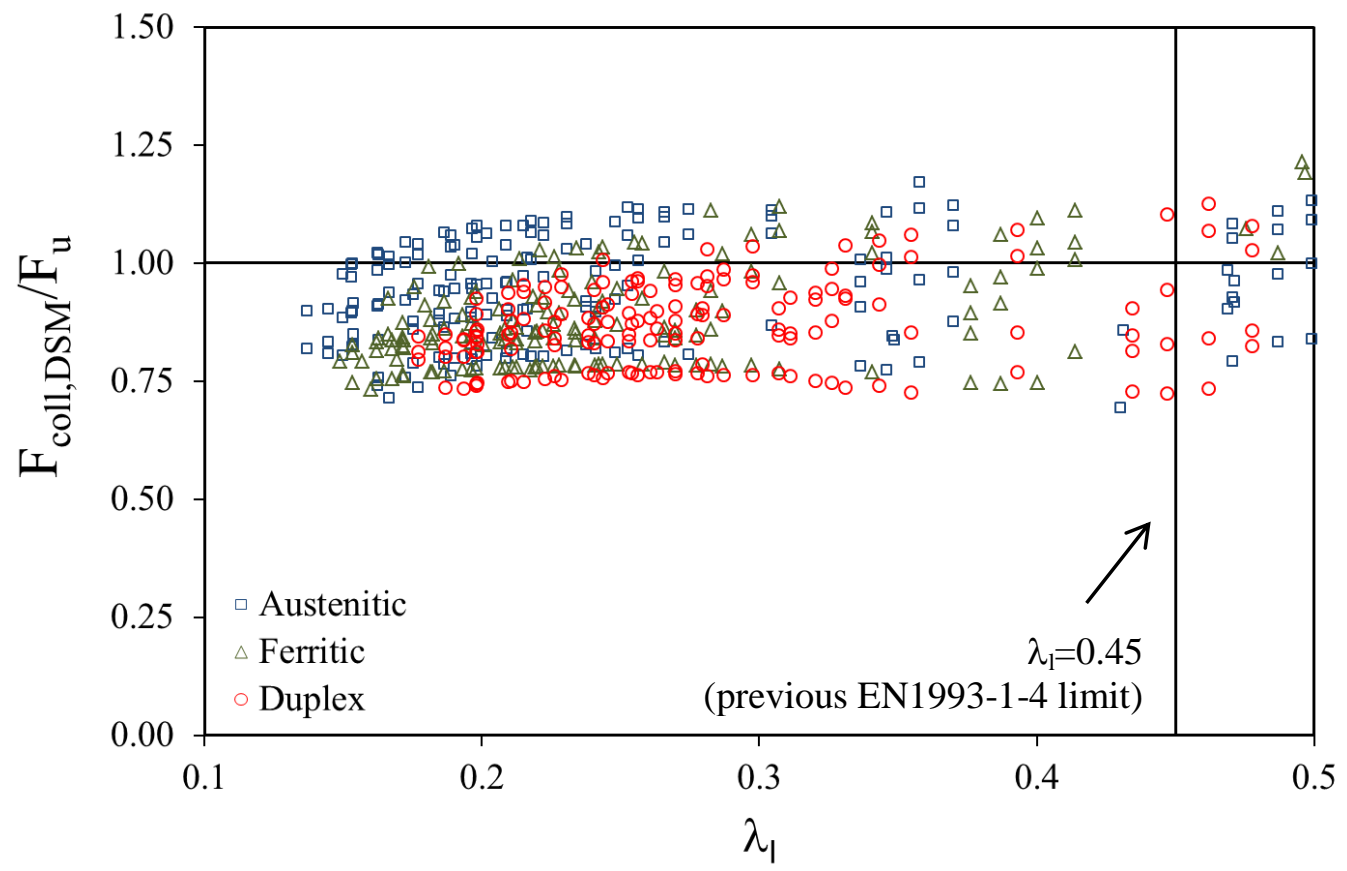

Figure 7. Assessment of the proposed DSM approach for indeterminate structures for different stainless steel grades.

\subsection{Reliability analysis}

Finally, the reliability of the proposed DSM plastic design approach is demonstrated through the corresponding statistical analysis for stainless steel RHS and SHS continuous beams. The validation has been derived according to EN1990, Annex D [23] specifications as described above in order to allow the comparison among the different methods and the summary of the most relevant statistical parameters is presented in Table 7. According to the results gathered in Table 7 the proposed DSM-based approach can also be safely applied for all stainless steel grades if the partial safety factor $\gamma_{M 0}$ currently codified in EN1993-1-4 [1] is considered, since the calculated $\gamma_{\mathrm{M} 0}$ values lay below 1.10. Given that the calculated partial safety factors are very close to 
the 1.10 limit, it is not expected the updated Class 1 limit in EN1993-1-4 [1] to provide results fulfilling the corresponding reliability requirements and has not been included in the analysis.

Table 7. Summary of the reliability analysis results for the proposed DSM approach for continuous beams according to Annex D in EN1990 and AISI-S100-12.

\begin{tabular}{cccccc}
\hline Grade & $\mathrm{b}$ & $\mathrm{V}_{\delta}$ & $\mathrm{V}_{\mathrm{r}}$ & $\gamma_{\mathrm{M} 0}$ & $\begin{array}{c}\text { Calculated } \\
\text { reliability index } \beta\end{array}$ \\
\hline Austenitic & 1.067 & 0.119 & 0.144 & 1.07 & 3.21 \\
Ferritic & 1.127 & 0.106 & 0.127 & 1.05 & 3.30 \\
Duplex & 1.141 & 0.100 & 0.116 & 1.06 & 3.03 \\
\hline
\end{tabular}

Nevertheless, and since the new proposal adopts the bending moment capacities calculated from the DSM approach proposed in [7], additional reliability analyses have been conducted. The procedure provided in section $\mathrm{F}$ of the North American Specification AISI-S100-12 [27] has been followed and the same statistical parameters corresponding to the material and geometrical variations have been adopted. Australian and American codes prescribe resistance factors $\phi$ equal to 0.9 for tubular cross-sections in bending with a target reliability index of $\beta_{0}=2.5$. In the calculation of the reliability indices the load data and factors from the Commentary of AS/NZS4600 [28] have been considered and a dead-to-live load ratio of 1/5 has been assumed. The calculated reliability indices for the DSM approach for austenitic, ferritic and duplex stainless steel RHS and SHS continuous beams are reported in Table 7. Considering the resistance factors $\phi$ prescribed in AS/NZS4673 [2] and SEI/ASCE 8-02 [3] equal to 0.9, results demonstrate that the proposed approach can be also safely applied to all the studied stainless steel grades according to AISI-S100-12 [27] since calculated indices are higher than the target reliability index $\beta_{0}=2.5$. 


\section{Conclusions}

This paper presents a comprehensive analysis on the behaviour and the prediction of ultimate resistance of stainless steel RHS and SHS continuous beams. Current EN1993-1-4 [1] provisions do not allow global plastic design in stainless steel structures despite their high ductility, and the failure of the structure is limited to the load at which the first plastic hinge is formed. The analysis demonstrated that ultimate capacity predictions calculated based on the first hinge formation result in a considerable conservatism due to strain hardening effects and the bending moment redistribution capacity of the beams. Therefore, the assessment and reliability analysis of the traditional global plastic design methods have been presented for the Class 1 cross-section limits currently provided in EN1993-1-4 [1] and that given in the previous version of the code. The analysis demonstrated that although the previous Class 1 limit $(\mathrm{c} / \mathrm{t} \varepsilon=25.7)$ can be safely applied for the partial safety factor $\gamma_{\mathrm{M} 0}$ provided in [1], the revised limit currently codified in [1] $(\mathrm{c} / \mathrm{t} \varepsilon=33)$ is too optimistic for ferritic and duplex stainless steel grades. Thus, it is recommended that the former Class 1 limit is adopted $(\mathrm{c} / \mathrm{t} \varepsilon=25.7)$ for traditional plastic design of stainless steel continuous beams.

It has also been demonstrated that including bending moment redistribution in capacity predictions is not enough since strain hardening effects play an important role for stocky cross-sections. The CSM for indeterminate structures was found to be an excellent design approach for all analysed stainless steel alloys, and has also been statistically validated. In addition, a new method based on the DSM bending capacity approach has been proposed. The method adopts the bases of the CSM approach for indeterminate structures, where the full DSM bending capacity is assigned to the critical hinge while reduced capacities (determined from an equivalent local slenderness) are adopted for the subsequent plastic hinges. The proposed method provides marginally better and more 
consistent results than the CSM approach for indeterminate structures and its reliability has been demonstrated through the corresponding statistical analyses.

Further research is necessary to extend this study to different and more general indeterminate structural configurations, such as frames, to validate expressions and reach more general conclusions.

\section{ACKNOWLEDGEMENTS}

Authors would like to acknowledge the funding from the Ministerio de Economía y Competitividad (Spain) under the Project BIA 2012-36373. The first author would also like to thank the financial support provided by the Secretaria d'Universitats i de Recerca del Departament d'Economia i Coneixement de la Generalitat de Catalunya i del Fons Social Europeu through the FI-DGR 2014 grant.

\section{REFERENCES}

[1] European Committee for Standardization. EN1993-1-4: 2006 + A1:2015. European Committee for Standardization Eurocode 3. Design of steel structures. Part 1-4: General rules. Supplementary rules for stainless steels. Brussels, Belgium, 2006.

[2] AS/NZS4673. Cold-formed stainless steel structures. Sydney: Standards Australia; 2001.

[3] Specification for the Design of Cold-Formed Stainless Steel Structural Members. ASCE Standard SEI/ASCE 8-02, Reston, VA, American Society of Civil Engineers, 2002.

[4] Afshan S. and Gardner L. The continuous strength method for structural stainless steel design. Thin-Walled Structures, 68, 42-49, 2013.

[5] Bock M., Gardner L. and Real E. Material and local buckling response of coldformed ferritic stainless steel sections. Thin-Walled Structures, 89, 131-141, 2015. 
[6] Rossi B. and Rasmussen K.J.R. Carrying capacity of stainless steel columns in the low slenderness range, Journal of Structural Engineering (ASCE), 139, 1088-1092, 2013.

[7] Arrayago I., Rasmussen K.J.R. and Real E. Full slenderness range DSM approach for stainless steel hollow cross-sections. Journal of Constructional Steel Research, 133, 156-166, 2017.

[8] European Committee for Standardization. EN1993-1-1. European Committee for Standardization Eurocode 3. Design of steel structures. Part 1-1: General rules and rules for buildings. Brussels, Belgium, 2005.

[9] Gardner L., Wang F.C., and Liew A. Influence of strain hardening on the behaviour and design of steel structures. International Journal of Structural Stability and Dynamics, 11(5), 855-875, 2011.

[10] Theofanous M., Saliba N., Zhao O., and Gardner L. Ultimate response of stainless steel continuous beams. Thin-Walled Structures, 83, 115-127, 2014.

[11] Real E. and Mirambell E. Flexural behaviour of stainless steel beams. Engineering Structures 28(6), 926-934, 2005.

[12] Arrayago I. and Real E. Experimental study on ferritic stainless steel simply supported and continuous beams. Journal of Constructional Steel Research, 119, 50-62, 2016.

[13] ABAQUS. ABAQUS/Standard user's manual volumes I-III and ABAQUS CAE manual. Version 6.12. Hibbitt, Karlsson \& Sorensen, Inc., Pawtucket, USA, 2012.

[14] Theofanous M. and Gardner L. Experimental and numerical studies of lean duplex stainless steel beams. Journal of Constructional Steel Research, 66(6), 816-825, 2010. 
[15] Rasmussen K.J.R. and Hancock, G.J. Design of cold-formed stainless steel tubular members. I: Columns. Journal of Structural Engineering (ASCE), 119(8), 2349-2367, 1993.

[16] Zhao O., Gardner L. and Young B. Behaviour and design of stainless steel SHS and RHS beam-columns, Journal of Constructional Steel Research, 106, 330-345, 2016.

[17] Arrayago I., Real E. and Gardner L. Description of stress-strain curves for stainless steel alloys. Materials and Design, 87, 540-552, 2015.

[18] Gardner L. and Theofanous M. Discrete and continuous treatment of local buckling in stainless steel elements. Journal of Constructional Steel Research, 64, 1207-1216, 2008 .

[19] Afshan S. and Gardner L. Experimental Study of Cold-Formed Ferritic Stainless Steel Hollow Sections, Journal of Structural Engineering (ASCE), 139(5), 717-728, 2013.

[20] Schafer B. and Pekoz T. Direct strength prediction of cold-formed steel members using numerical elastic buckling solutions. Thin-Walled Structures, Research and Developments, New York, Elsevier, 127-44, 1998.

[21] Su M., Young B. and Gardner L. Continuous beams of aluminium alloy tubular cross sections. II: parametric study and design, Journal of Structural Engineering, ASCE, 141(9): 04014233, 2015.

[22] Schafer B. and Ádány S. Buckling analysis of cold-formed steel members using CUFSM: conventional and constrained finite strip methods, Proceedings of the 18th International Specialty Conference on Cold-formed Steel Structures, 39-54, 2006.

[23] European Committee for Standardization. EN1990. European Committee for Standardization Eurocode. Basis of structural design. Brussels, Belgium, 2005. 
[24] Tankova T., Simoes da Silva L., Marques L., Rebelo C. and Taras A. Towards a standardized procedure for the safety assessment of stability design rules. Journal of Constructional Steel Research, 103, 290-302, 2014.

[25] Afshan S., Francis P., Baddoo N.R. and Gardner L. Reliability analysis of structural stainless steel design provisions. Journal of Constructional Steel Research, 114, 293-304, 2015.

[26] EN10080-4, Stainless steels part 4: Technical delivery conditions for sheet/plate and strip of corrosion resisting steels for construction purposes. European Committee for Standardization, 2009.

[27] AISI. AISI- S100-12. North American specification for the design of cold-formed steel structural members. American Iron and Steel Institute (AISI). Washington, D.C., 2012.

[28] AS/NZS4600. Cold-formed steel structures. Sydney: Standards Australia, 2005. 